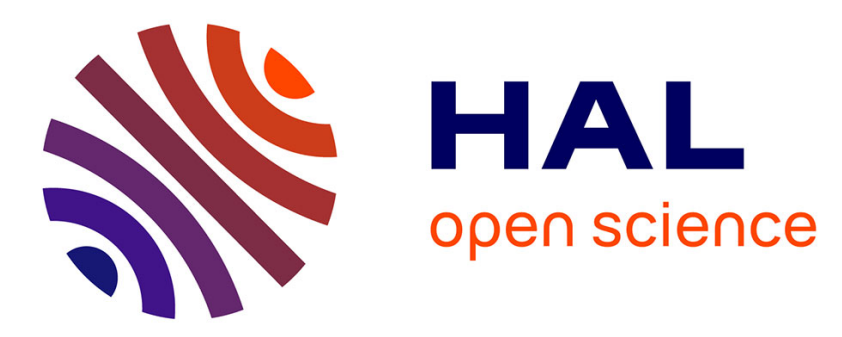

\title{
Core-Shell Polymer Adhesive for Aluminized Coatings: From Improved Barrier Properties to Commercial Formulation
}

\author{
Barbara Rezende Lara, Keltoum Ouzineb, Timothy Frederick Llewellyn \\ Mckenna
}

\section{To cite this version:}

Barbara Rezende Lara, Keltoum Ouzineb, Timothy Frederick Llewellyn Mckenna. Core-Shell Polymer Adhesive for Aluminized Coatings: From Improved Barrier Properties to Commercial Formulation. Macromolecular Materials and Engineering, 2019, 304 (10), pp.1900148. 10.1002/mame.201900148 . hal-02414140

\author{
HAL Id: hal-02414140 \\ https://hal.science/hal-02414140
}

Submitted on 12 Nov 2020

HAL is a multi-disciplinary open access archive for the deposit and dissemination of scientific research documents, whether they are published or not. The documents may come from teaching and research institutions in France or abroad, or from public or private research centers.
L'archive ouverte pluridisciplinaire HAL, est destinée au dépôt et à la diffusion de documents scientifiques de niveau recherche, publiés ou non, émanant des établissements d'enseignement et de recherche français ou étrangers, des laboratoires publics ou privés. 


\title{
Core-Shell polymer adhesive for aluminized coatings: From improved barrier properties to commercial formulation
}

\author{
Barbara Rezende-Lara ${ }^{1}$, Keltoum Ouzineb ${ }^{2}$, Timothy F.L. McKenna ${ }^{1, *}$ \\ ${ }^{1}$ C2P2 - LCPP Group, UMR5265 CNRS, Université de Lyon, ESCPE Lyon, Bat 308F, 43 Bd \\ du 11 novembre 1918, F-69616, Villeurbanne, France \\ *E-mail: timothy.mckenna@univ-lyon1.fr \\ ${ }^{2}$ Toray Films Europe, Place d'Arménie, 01700 Saint-Maurice-de-Beynost, France
}

\begin{abstract}
The development and formulation of core-shell latex-based adhesives to improve the adhesion of aluminium to poly(ethylene terephthalate) (PET) films and enhance the permeability of the final laminate to oxygen and water is described. All particles had a soft acrylic component (the shell in core-shell particles) to improve adhesion, and occasionally a hydrophobic core to enhance the permeability. The performance of the different latexes was compared to that of a commercially available reference material. The coatings formed by core-shell nanoparticles presented a lower permeability to water than the particles synthesized in the absence of the seed, whilst the permeability to oxygen was found to be mainly related to the correct deposition of the metallic layer. In terms of the industrial formulation, it was found that a limited amount of a wetting agent (WA) is needed to ensure the correct spreading of the latex onto the PET substrate because of the low levels of surfactant used for the matex production. This compound a positive effect on the adhesive strength of the coating. A curing agent also improved barrier properties, but the optimal level of this compound was dependent on the degree of cross-linker used in the base latex.
\end{abstract}

KEYWORDS: packaging, barrier, permeability, adhesive, polyethylene terephthalate, coating

\section{Introduction}


The ability to act as a barrier to different substances is of fundamental importance for a material used in packaging. Polymers have many advantages properties for use in a wide range of packaging materials, however their barrier properties to the passage of small molecules such as water, oxygen and other gases are often insufficient. In the specific case of food packaging, simultaneously preventing the diffusion of both water and oxygen is essential but can be difficult due to the differences between the transport mechanisms of these species through polymers used for this purpose. Certain semi-crystalline polymers such as polyvinylidene chloride (PVDC) and polyvinyl chloride(PVC) do present good barrier properties to both water and oxygen, while others such as polyvinyl alcohol (PVOH) provide a good barrier to oxygen in the absence of humidity. ${ }^{1-5}$ However it is not desirable to use chlorinated monomers in food packaging, and PVOH fails when water is present.

These difficulties mean that it is common to combine several layers of different materials, in particular by laminating a polymer film with a metallic layer, ${ }^{6-8}$ in order to prevent the diffusion of the two molecules in question. The main difficulty associated with this approach is the need for creating a smooth, defect-free interface between the materials composing the laminate. This is because incompatibilities between the different phases will often create defects that present preferential pathways for the diffusion of small molecules. The solution to this problem is the addition of a third, intermediate layer that promotes adhesion of the metal layer to the polymer film. It is still desirable that this third layer also impede the transport of water and oxygen, and in addition it should be able to do so at temperatures used in sterilizing the composite material. Such layers often take the form of water-based acrylic latexes.

A polymer that can form a film and be used as coating must not be intrinsically rigid, as this will impair the homogeneity of the film, and consequently its ability to properly work as 
a cohesive barrier. Coatings are therefore often constituted of monomers that will form relatively soft co-polymers. However, polymer chains in a rubbery state tend to be mobile, and have a higher free free volume than glassy polymers, thereby facilitating transport of small molecules through them. ${ }^{9}$

Since it is not possible to compromise one property for the sake of the other, so an interesting approach is to insert two distinct phases using core-shell structured particles. Core-shell (CS) nanoparticles are the combination of two different phases with well-defined properties. For instance, in the present case, it seems promising to use a hard-core / soft-shell system to ensure better mechanical and barrier properties in the core, protected by a soft shell responsible for forming a homogeneous, defect free film. ${ }^{10-16}$

Core-shell particles are almost exclusively made using a seeded semi-batch emulsion polymerization process. ${ }^{17-20}$ Seed properties ${ }^{21-22}$ and process control ${ }^{23-24}$ will play a major role in determining the final morphology of the latex particles. The seeds can either be synthezied separately and stored, or in the case of a "one-pot" process, they can be made in a first step, then a second feed policy is used to make the shell right away. The work presented here relies on the first approach, because it allows a better repeatability of the process, since the same seed batch may be used for several runs. The idea is to create a closer interface between materials that have different properties and make them work together in order to minimize the compromises to be made when seeking antagonistic properties in a same system. Working with a core-shell morphology avoids extra formulation and mixing steps, and consequently limits the presence of contaminants and side products.

The final morphology of a particle is a function of thermodynamics and kinetics, and several structures can be produced ${ }^{25-29}$ by varying different process parameters. In the case of a two-step process intended to make polymers of a different nature, whether or not the second polymer phase remains on the surface of the seeds depends on the amphiphilic character of 
the reactive radicals formed in the aqueous phase. Chains initiated by persulfates tend to anchor themselves on the particles surface because their solubility in the aqueous media is compromised by the growth process. They will remain on the surface if chain propagation by monomer addition prevents the diffusion of the macro-chain, restraining the penetration in the core of the particle. Chain growth on the surface of the particles adds itself to all the heterogeneities of the system, which comprises the hydrophilicity of the polymer and also its compatibility with the seed. In order to form a core-shell one needs to choose the shell and core materials in such a way that the resulting particles have controlled morphology, in the order one desires; i.e. the shell should be slightly more hydrophilic than the core. The interested reader is referred to the following references to find more details concerning this matter. $^{30-34}$

First, the formulation will be important in terms of establishing the thermodynamic equilibria that will define how the particle will be structured. The hydrophilicity of the monomers, the initiator, the presence of crosslinkers or chain transfer agents, as well as the nature of the process, (batch, semi-batch, among others) will be critical in determining the final structure. The morphology of core-shell particles is thus the result of a process in which the system seeks the minimum possible energy configuration, and is associated with the difference between the surface tensions of the phases of which the system is composed..$^{30,35}$ Details can be found elsewhere for the effect of: surfactant, ${ }^{36-37}$ crosslinker, ${ }^{17,38-44}$ glass transition temperature $\left(T_{g}\right),{ }^{43}$ and polymerization process $^{36,44}$ on the final morphology of polymeric systems.

As mentioned above a packaging material must have barrier properties but polymers tend to show considerable permeability to small molecules, so the main challenge in working with them is to find an effective way to overcome this issue. The permeability of a molecule through a physical barrier is characterized by a permeability coefficient, which is defined as 
the volume of penetrant that goes through a unit thickness of a material per unit area at constant temperature. The driving force governing the permeation process is the difference in chemical potential of the media on either side of the physical barrier, hence the transport process is a way to equalize the environment in the two phases separated by the polymeric film. ${ }^{45}$ This means that the flux of a molecule through a material will depend on the ability of this material to sorb the penetrant on the upstream side of the physical barrier. Permeability is basically the product of two different processes: (1) the dissolution of the permeant molecules in the upstream/downstream faces of the polymeric film; and (2) the molecular diffusion of those same molecules through the polymeric matrix. ${ }^{46-48}$ The dissolution step, which can be described by Hansen solubility parameters, will be dependent mainly on the chemical affinity between the permeant and the barrier. The diffusion process can be described using Fick's first law of diffusion ${ }^{49,50}$, which states that for low concentrations of ideal penetrants, the flux ( $J$ ) will be proportional to the concentration gradient across the barrier ( $\partial c / \partial x$ ), where the proportionality constant is the diffusion coefficient of the penetrant. A high tendency of the penetrant to sorb and a high value of its diffusion coefficient will contribute to a high permeability. The diffusivity of the penetrant will depend to a great extent on the free volume of the polymer through which it is diffusing. ${ }^{51}$ The permeation process takes place in the amorphous phase of the polymeric film, as the interstitial volume of the crystalline fraction is so low that sorption and diffusion can occur only in the amorphous phase. ${ }^{14}$ This in turn implies that it is necessary to consider the state of this matrix, whether it is above or below the glass transition $(T g)$, and whether or not it is crosslinked. ${ }^{52-55}$ In short, factors that restrict the mobility of the chains in the amorphous fraction of the polymer can decrease the diffusivity, and thus permeability of penetrants.

PET is one of the most widely used polymers in the packaging industry as it is easily recycled and processed, and has physicochemical properties (transparent, semi-crystalline 
thermoplastic resin) which make it suitable for a wide range of applications. Nevertheless, it does not have good barrier properties, which means that it must be combined with some other sort of material that furnishes a resistance against the movement of penetrants between the two different environments. One particularly useful way to do this is to coat the PET with a layer of aluminium. The main challenge in pursuing this approach is to promote the adhesion between the PET substrate and the metallic aluminium, which means that it is necessary to understand how the polymeric surface interacts with the metal. Adhesion is fundamentally dependent upon the smoothness of the surfaces in which the interaction should take place, as well as on the chemical nature of the surface and adhesive. The influence of the surface properties, while important are beyond the scope of this work. Very briefly, the surface needs to have a minimum level of roughness to promote adhesion, but not so much that this impedes the formation of a uniform, defect free film. A review on metal surface characteristics, cleaning and treatments is presented in detail elsewhere. ${ }^{56}$

In addition to being regulated by the physical nature of the surface, the adhesion process of a polymer to an aluminium substrate is based on the interaction between the oxygenated groups of the polymer and the metallic aluminium. In the absence of oxygenated groups, adhesion may be achieved to a lesser extent with another electronegative groups, for example nitrogen groups. A non-polar (or weakly polar) polymer such as PET is unlikely to interact strongly with aluminium, since the metal will not find many functional groups able to provide a favourable physical interaction. On the other hand, if the polymer has enough polar groups to ensure adhesion and avoid hydrophilicity, the metal will interact preferentially with the functional groups keeping the structure together by means of hydrogen bonds. Thus, the insertion of a functional latex to promote the adhesion between the main polymer and metallic aluminium, is a permanent and useful way to improve the adherence between these materials. Nevertheless, it is important to control the composition and structure of the latex 
with this approach, since an excess of oxygenated functions will increase the hydrophilicity of the material, leading consequently to delamination. It is therefore expected that the polymer to be used as the adhesion promoter will be synthesized with in such a way as to ensure that the functionalities will be sufficient but not excessive.

This was the motivation for the development of the core-shell structure in this work. The main idea was to create a more intimate contact between the different phases composing the system, which were designed to have a hydrophobic core containing the hydrophobic monomer (styrene, STY in our case) that would be responsible for water resistance, and a functionalized shell containing methyacrylic acid (MAA) expected to promote the adhesion to metallic aluminium, the latter being responsible for the virtually complete barrier against the small permeants. In the following we will explore different formulations for an intermediate adhesive polymer based on the use of a core-shell morphology and will then formulate the adhesive for use in an industrial coating process. Finally, the barrier and adhesive properties of the unformulated and formulated latexes will be evaluated.

\section{Experimental}

\section{Materials}

Polymer grade monomers methyl methacrylate (MMA), ethyl acrylate (EA), methacrylic acid, styrene and butyl acrylate (BA), as well as the crosslinker ethylene glycol eimethacrylate (EGDMA, $>98 \%$ ), the initiator ammonium persulphate (APS), the ionic surfactant sodium dodecyl sulfate (SDS), and the salt sodium bicarbonate were all purchased from Sigma Aldrich and used as supplied.

Wisester N530, a sulphonated polyester wetting agent, was supplied as a $30 \% \mathrm{wt}$ in solution (Bozzetto Group, Filago, Italy), hexamethoxymethylmelamine (HMMM tradename Cymel 303) was used as the curing agent (>98\% wt) and was obtained from 
Allnex. Methacrylamidoethyl Ethylene Urea (MAEEU, tradename Sipomer WAN II) was used as a functional monomer $(65 \% \mathrm{wt})$ and was obtained from from Solvay. All reagents were used as received. The structures of HMMM, MAEEU and Wisester are shown in Scheme 1 (a) and (b), respectively.

(a)<smiles>COCN(COC)c1nc(N(COC)COC)nc(N(COC)COC)n1</smiles>

(b)<smiles>C=C(C)C(=O)ONCCN1CCNC1=O</smiles>

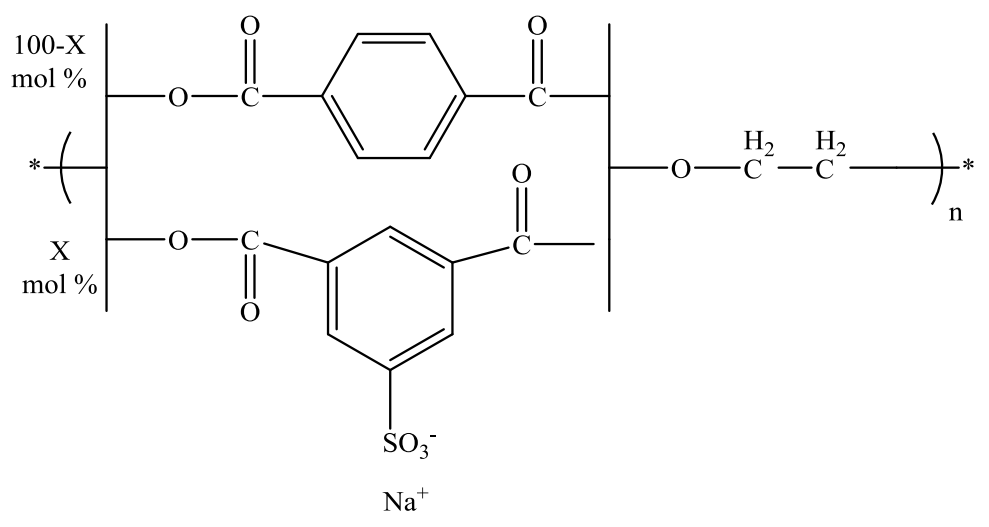

Scheme 1. Structures of (a) HMMM, (b) MAEEU and (c) Wisester where $\mathrm{X}$ is 20.

All the water used on the polymerizations was deionized (D.I.).

\section{Methods}

Two sets of latex were synthesized in order to evaluate: (1) the effect of the crosslinker and its concentration; and (2) the effect of seed presence on the barrier properties of the final coating. The first set, which will be labelled BR_Sx, where ' $x$ ' is the mass fraction of crosslinker used in the system, was synthesized in the absence of seed particles, and was not a core-shell system. In fact $\mathrm{S}$ signifies "Shell", as these latexes are made from the same material as the shell in the second series. The second set will be labelled BR_CSx, ' $x$ ' also 
stands for the amount of crosslinker, but here core-shell (CS) nanoparticles will be presented. In other words, the monomeric composition of BR_S10 is identical to the composition of the shell of BR_CS10. The seed latex will be labelled BR_C.

Seed synthesis: For reasons related to the specific application of interest, the poly(styreneco-butyl acrylate) latex seeds were to have particle sizes between 40 to $70 \mathrm{~nm}$, and around $24 \% \mathrm{v} / \mathrm{v}$ solid content. Experience has shown that larger particles can be detrimental to the uniformity of the metallized coating. The polymerizations were carried out in a $1 \mathrm{~L}$ jacketed glass reactor with 4 entries, equipped with an anchor-type glass agitator, reflux condenser system and a valve in the bottom for sampling. The temperature of the reactor was set to $72^{\circ} \mathrm{C}$ and stirring speed was kept constant at $250 \mathrm{rpm}$. Reaction temperature was determined based on the half-life time $\left(t_{1 / 2}\right)$ of the initiator. ${ }^{51}$ Emulsifier, water, monomer and buffer were injected in the reactor and purged under nitrogen flow for 30 minutes while the temperature of the thermostatic bath (HAAKE F6) was raised to $72^{\circ} \mathrm{C}$. The initiator was separately dissolved in distilled deionized water, and the solution was also purged under nitrogen flow during 30 minutes at ambient temperature. When the reaction temperature was reached, the initiator was added in a single shot using a syringe. The reaction was considered started at this point. Samples were periodically withdrawn and polymerization was quenched by immersing sample flasks into an ice bath.

Core-shell synthesis: In the semi-batch step, part of the initiator was solubilized in $50 \mathrm{~mL}$ of distilled deionized water and it was kept under nitrogen flow during $30 \mathrm{~min}$. Portions (quantities can be found in 
Table 1) of the emulsifier and of the buffer were separately solubilized in 150 and $100 \mathrm{~mL}$ of distilled deionized water, respectively, and added to the reactor with the seed and the remaining water. The rest of emulsifier and salt, along with the seed were introduced into the reactor vessel at the very beginning of the procedure. The temperature of the reactor was set to $72^{\circ} \mathrm{C}$ and stirring speed was kept constant at $250 \mathrm{rpm}$. The reactor vessel was kept under nitrogen flow until the polymerization was complete. The procedure used two tanks. The first one contained a mixture of some or all of MMA, EA, MAA and EGDMA (not all the reactions used all four monomers), in a proportion chosen to obtain predetermined $\mathrm{Tg}$ values. Three levels of cross-linker were considered here, with the maximum value being close to the limit where films can no longer form. This mixture was fed into the reactor by means of a piston pump. The feeding time ranged from 100 to 180 minutes. The second tank contained a solution of SDS and APS, solubilized in $60 \mathrm{~mL}$ of distilled deionized water. This solution was fed at a rate of $15 \mathrm{~mL}$ of solution per hour using a Watson-Marlow Sci-Q300 peristaltic pump. The monomer feed (tank one) to the reactor was started right after the initiator shot, and the feed of buffer/surfactant/initiator solution began 10 minutes after that. The reaction was considered to have begun when the first drop of monomer touched the reactional media. Samples were periodically withdrawn and polymerization was quenched by immersing sample flasks into an ice bath. 
Table 1 summarizes the recipe used in the polymerizations above described.

Table 1. Recipes used in the evaluation of crosslinking content and core presence in the properties of the material.

\begin{tabular}{|l|l|l|l|l|l|l|l|}
\hline & Core & BR_S0 & BR_S10 & BR_S20 & BR_CS0 & BR_CS10 & BR_CS20 \\
\hline \multirow{4}{*}{$\begin{array}{l}\text { Core } \\
\text { Seed }(g) \\
P(S T Y-c o-B A)\end{array}$} & - & - & - & 180 & 180 & 180 \\
\hline \multirow{4}{*}{$\begin{array}{l}\text { Initial } \\
\text { Charge }\end{array}$} & Water $(g)$ & 390 & 390 & 390 & 315 & 315 & 315 \\
\cline { 2 - 9 } & SDS $(g)$ & 0.60 & 0.60 & 0.60 & 0.60 & 0.60 & 0.60 \\
\cline { 2 - 9 } & APS $(g)$ & 1.90 & 1.90 & 1.90 & 1.90 & 1.90 & 1.90 \\
\cline { 2 - 9 } & NaHCO $(g)$ & 1.90 & 1.90 & 1.90 & 1.90 & 1.90 & 1.90 \\
\hline \multirow{2}{*}{\begin{tabular}{l} 
One \\
\cline { 2 - 8 }
\end{tabular}} & Water $(g)$ & 60 & 60 & 60 & 60 & 60 & 60 \\
\cline { 2 - 9 } & SDS $(g)$ & 0.12 & 0.12 & 0.12 & 0.12 & 0.12 & 0.12 \\
\hline
\end{tabular}




\begin{tabular}{|l|l|l|l|l|l|l|l|}
\hline \multirow{5}{*}{} & APS $(\mathrm{g})$ & 0.26 & 0.26 & 0.26 & 0.26 & 0.26 & 0.26 \\
\cline { 2 - 8 } & $\mathrm{NaHCO}_{3}(\mathrm{~g})$ & 0.26 & 0.26 & 0.26 & 0.26 & 0.26 & 0.26 \\
\cline { 2 - 8 } & $\begin{array}{l}\text { Feed rate } \\
(\mathrm{mL} / \mathrm{min})\end{array}$ & 0.25 & 0.25 & 0.25 & 0.25 & 0.25 & 0.25 \\
\hline \multirow{5}{*}{$\begin{array}{l}\text { Tank } \\
\text { Two }\end{array}$} & MMA & 117 & 91 & 63.0 & 117 & 91 & 63.0 \\
\cline { 2 - 9 } & EA & 118 & 120 & 124 & 118 & 120 & 124 \\
\cline { 2 - 9 } & \begin{tabular}{l} 
EGDMA \\
\cline { 2 - 8 }
\end{tabular} & 4.80 & 4.80 & 4.80 & 4.80 & 4.80 & 4.80 \\
\cline { 2 - 9 } & $\begin{array}{l}\text { Feed rate } \\
\text { (g/min }\end{array}$ & 2.01 & 1.75 & 2.00 & 1.24 & 1.21 & 2.40 \\
\hline
\end{tabular}

Latex Formulation for Barrier Testing at Industrial Scale. The formulations were prepared by diluting a suitable amount of latex with deionized water under magnetic stirring. All the mixing steps must be carefully performed in order to avoid the formation of foam. The wetting agent was slowly added to the diluted latex under gentle agitation. The addition of the curing agent is the critical step of the process and it takes place after adding the wetting agent (if this last is present in the formulation). The resin used in this work is a very hydrophobic, very viscous compound, therefore its addition must be done slowly and at the edge of the vortex formed by the magnetic stirring. Under such conditions, the crosslinker is able to correctly mix into the latex without phase separation. After the insertion of all the compounds the mixture was left under agitation for 2 hours.

Film deposition: The industrial scale process starts with dried PET pellets (the presence of water in the material leads to problems such as the breaking of the film during the stretching step). The pellets are melted, then the melt is moulded over a series of metal rolls with controlled speed and temperature. The thickness of the extruded film can be controlled in the process by changing the speed of the rolls. Before the coating is applied, the PET film may be subjected to surface treatments, the most commonly used of which is a corona treatment. The film is then coated with a latex having a defined solid content that depends on the thickness 
required for the final dried film. After the deposition of the coating, the laminate is sent to an oven at a controlled temperature, where it is biaxially stretched.

In both instances, the metallization process was performed externally and details about this step can be found elsewhere. ${ }^{58}$

\section{Characterization}

Thermal properties were analysed with a DSC 3 from Mettler Toledo employing two different temperature programs. In the first one the temperature ranged between $-10^{\circ} \mathrm{C}$ and $200^{\circ} \mathrm{C}$, with a heating rate of $15^{\circ} \mathrm{C} / \mathrm{min}$. The second program variated from -40 to $150^{\circ} \mathrm{C}$ at a heating rate of $10^{\circ} \mathrm{C} / \mathrm{min}$. In both cases, second scan was considered.

MFFT was measured according to ASTM D2354. The latex was placed on a metallic substrate to which a temperature gradient, ranging from 10 to $90^{\circ} \mathrm{C}$ was applied using two thermostatic baths (more narrow intervals were used inside this range depending on the latex to be analysed). MFFT is determined at the position of the substrate where the film goes from a brittle white powder to a transparent uniform material and relating it to the correspondent temperature.

For transmission electron microscopy (TEM) analysis, diluted latex (around 3\% wt solids) samples were dropped on a carbon/formvar-coated copper grid and dried under air overnight. For cryo- TEM, diluted ( $6 \%$ wt solids) latex samples were placed on carbon-coated copper grid treated with plasma, and frozen with liquid nitrogen. TEM and cryo-TEM images were made at an accelerating voltage of 80 and $120 \mathrm{kV}$ respectively with a Philips CM120 transmission electron microscope at the Centre Technologique des Microstructures $(\mathrm{CT} \mu)$, platform at the Université Claude Bernard Lyon 1, Villeurbanne, France.

Water and oxygen permeability analyses were performed by placing the coated PET as a sealed semi-barrier between two chambers at ambient atmospheric pressure. One chamber is 
slowly purged by a stream of nitrogen. The other chamber is purged with a humidified gas. As moisture permeates through the film into the nitrogen carrier gas, it is transported to the detector where the concentration is recorded. The permeability is determined considering the flow at steady state and applying Equation 1.

$P=\frac{J \cdot l}{\Delta p}$

\section{Equation 1}

Where $J$ is the flow rate of the penetrant (WTR - water transmission flow and OTR oxygen transmission flow), $l$ is the film thickness and $\Delta p$ is the pressure drop across the film. The $\mathrm{O}_{2}$ transmission rates of the coated films (approximate dry thickness $50 \mu \mathrm{m}$ ) were measured using a MOCON Oxtran-2/20 instrument, following the ASTM Standard Method D 3985 at $\mathrm{RH}$ equals to $0 \%$ and $23^{\circ} \mathrm{C}$. Water transmission rate was measured at $38^{\circ} \mathrm{C}$ and RH of 90\%, following ASTM F1249, and using a MOCON PERMAT-RAN-W 3/31 instrument. The reference was the uncoated PET film.

Adhesion tests were performed following the procedure described in ASTM D882. The samples were prepared by heat lamination, then submitted to peel tests. The adhesion force was measured by peeling-off the metal layer from the PET substrate by sealing the metal to ethylene acrylic acid (EAA) adhesive. The EAA adhesive was laminated to the metallized side of the substrate by applying a pressure of $1 \mathrm{MPa}$ at a temperature of $105^{\circ} \mathrm{C}$ for $20 \mathrm{~s}$ by means of a hydraulic press. The sealed samples were fixed to an Aluminium plate using a double-sided adhesive tape, with the PET side oriented towards the aluminium plate. The peel tests were performed by peeling the EAA from the laminated in a tensile tester LR5K LLOYD Instruments. The samples were fixed at the clamps of the testing machine. The peel-off angle was set to $180^{\circ} \mathrm{C}$ and the peel rate was $10 \mathrm{~mm} / \mathrm{min}$. The adhesion force was defined as the force necessary to separate the metal layer from the PET substrate. The force was recorded as a function of the displacement of the upper clamp and the values were 
expressed in $\mathrm{N} / 38 \mathrm{~mm}$ (38mm was the width of the test samples). An average of three measurements was considered. ${ }^{58}$

\section{Results}

The glass transition temperature ( $T g$ ) has been found to be an important parameter when one discusses particle morphology, as the $T_{g}$ of the seed can for instance influence the trapping of oligomers. For instance Karlsson et $a l^{43}$ evaluated the impact of seed $T_{g}$ on nanoparticle morphology. They concluded that depending on the $T_{g}$ of the core, polymer radicals will be more or less prone to penetrate inside it. They ranked systems into three classes based on the fractional penetration value (defined as the ratio between the distance penetrated by the radical and the seed radius). Class 1 describes the systems containing radicals are able to fully penetrate the seed, Class 2 is an intermediate state, which covers radicals of partial penetration, and Class 3 is represented by strongly limited penetration radicals. The morphology, and consequently the properties of the latex resulting from the seeded semi-batch emulsion polymerization will be dependent on the capacity of the growing radicals to penetrate the seed particles. Radicals unable to penetrate the seed particles will be more likely to polymerize in the water phase, forming homogeneously nucleated particles that can flocculate onto the seed particles. In this case, the formation of two separate phases in the particles would be expected, and we will obtain a core-shell morphology. On the other hand, if the radical is able to penetrate to some extent inside the seed, little (or no) phase separation should be observed, and core-shell nanoparticles may or may not be formed, depending on the degree of penetration. Table 2 summarizes the theoretical $T_{g}$, calculated with the Fox equation, and the $T_{g}$ measured experimentally.

Table 2. Nanoparticles thermal properties evaluation and thickness estimation by cryo-TEM. 


\begin{tabular}{|c|c|c|c|c|c|}
\hline \multirow[b]{2}{*}{ Latex } & \multirow{2}{*}{$\begin{array}{l}\text { Theoretical } \\
\text { Shell } \\
\text { Thickness } \\
\text { (nm) }\end{array}$} & \multirow{2}{*}{$\begin{array}{c}\text { Measured } \\
\text { Shell } \\
\text { Thickness } \\
\text { (nm) }\end{array}$} & \multirow{2}{*}{$\begin{array}{c}\text { MFFT } \\
\left({ }^{\circ} \mathrm{C}\right)\end{array}$} & \multicolumn{2}{|c|}{$T_{g}\left({ }^{\circ} \mathrm{C}\right)$} \\
\hline & & & & Theoretical $^{\mathrm{c}}$ & Experimental \\
\hline BR_C & - & - & - & 80 & $82 \pm 2$ \\
\hline BR_S0 & - & - & 37 & 30 & $32 \pm 2$ \\
\hline BR_S10 & - & - & 52 & 30 & $40 \pm 2$ \\
\hline BR_S20 & - & - & & 30 & $64 \pm 2$ \\
\hline BR_CS0 & 55 & 30 & 38 & \multirow{3}{*}{$\begin{array}{l}\text { Dependent } \\
\text { on the } \\
\text { morphology }\end{array}$} & $32 \pm 2$ \\
\hline BR_CS10 & 56 & 36 & 52 & & $42 \pm 2$ \\
\hline BR_CS20 & 84 & 21 & & & $64 \pm 2$ \\
\hline
\end{tabular}

a - Calculated by the difference between P(STY-co-BA) diameter and final particle diameter measured by TEM and cryo-TEM respectively. b-Measured from TEM images. $\mathrm{c}$ - estimated by the Fox equation.

The minimum film forming temperature (MFFT) is an important parameter to be studied when good optical properties and defect free films are required. In the present work, the values of MFFT (Table 2) measured for the core-shell products from the seeded semi-batch emulsion polymerizations were very similar to the values found for the seed-free latex. This may be a good indication that the $\mathrm{P}(\mathrm{MMA}-\mathrm{co}-\mathrm{EA}-\mathrm{co}-\mathrm{MAA})$ is located on the outer shell of the particles. Theoretical $\mathrm{Tg}$ was estimated by using Fox Equation. ${ }^{59}$ Similarly to MFFT, for cross-linked particles the experimental $T g$ was found to be dependent only on the outer phase. Stubbs et al. ${ }^{54}$ evaluated the effect of the amount of EGDMA on core-shell nanoparticles, and they showed that at crosslinker concentrations below 1\%, two distinct glass transition are observed, which are correspondent to the different phases of core and shell. On the other hand, increasing the amount of cross-linker up to $10 \%$ meant that the phase separation is no longer pronounced, and the glass transition becomes a broad single peak indicating significant interpenetration of the polymer networks (IPN). This can explain the reason why our analysis only showed a single glass transition that increased with the amount of EGDMA. 
Up to a certain amount of EGDMA, this compound is able to prevent the phase separation, which explains why only one $T_{g}$ value was observed.

Microscopy analyses were performed in order to evaluate the real particle diameter, the related polydispersity index and to visualize the morphology of the particles. The images shown in Figure 1 correspond to the core-shell particles analysed by cryo-TEM and TEM.

Particles synthesized without EGDMA are basically composed of a shell surrounding a single particle. TEM analysis of polymers presenting low $T g$ leads to the melting of the softer phase, which may complicate the visualization of the particle outer boundary. Nevertheless, by observing the image of the particles BR_CS0 for example, it is possibly to see a well-defined 'Honey-comb' structure formed by the junction of neighbour particles during film formation. Moving along, particles from run BR_CS10 show some particularities. Once again, it is possible to identify the core shell-structure. This effect is pronounced for the particles synthesized with more EGDMA, in which it is possible to observe what seems to be multi-particle structures formed by the interpenetration of two or more neighbouring particles. A higher amount of crosslinker appears to correspond to the formation of a poorly defined structure between the core and the shell. In other words, the presence of EGDMA might lead to the growing of new polymer chains in the core by trapping oligomers and reducing their diffusion to aqueous phase. This mobility restriction could create an intermediate phase that is composed of P(MMA-co-EA-co-MAA) chains that have deeply penetrated into the $\mathrm{P}(\mathrm{STY}-\mathrm{co}-\mathrm{BA})$ seed. This may also explain the difficulty of observing a $T g$ specific to the core in our DSC analyses. 
cryo-TEM

BR_CS0 - O EGDMA

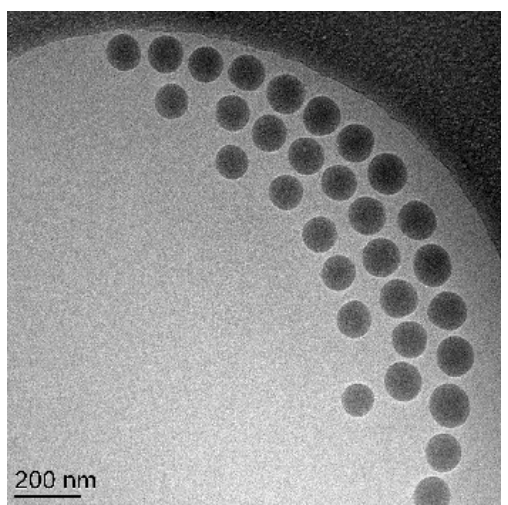

BR_CS10 - 24 g EDGMA
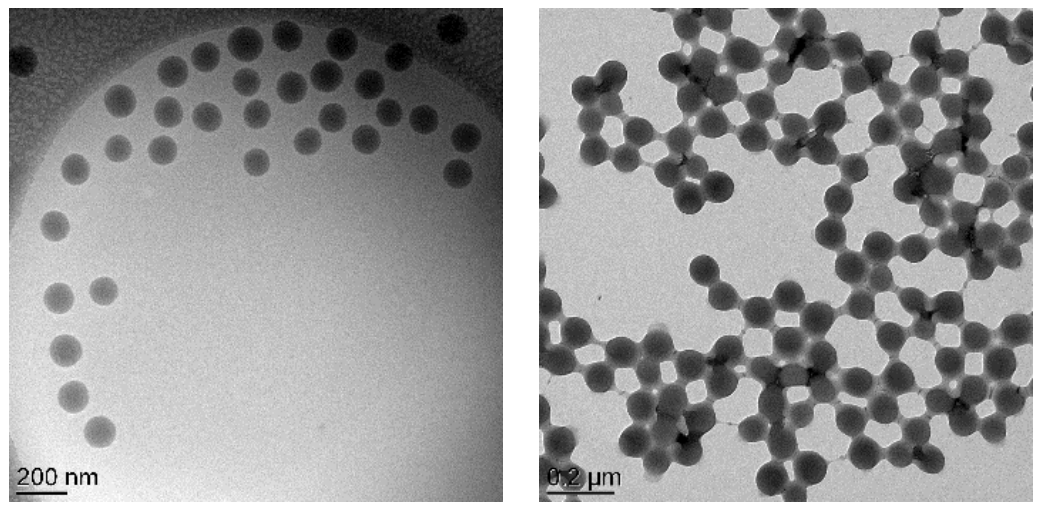

BR_CS20 - 48 g EGDMA
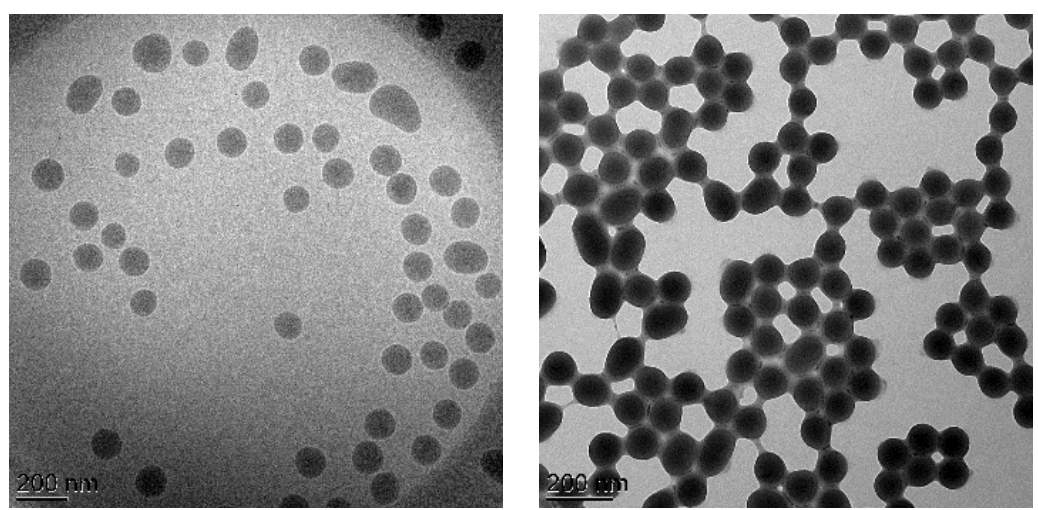

Figure 1. Morphological analysis of the seed particles and core-shell nanoparticles by cryoTEM and TEM.

The main parameter governing the diffusion through a polymeric matrix is the availability of free volume (i.e. empty spaces) in the polymeric matrix, as well as their mobility. Therefore, 
including compounds such as cross-linkers that have the function of preventing this mobility and reduce the free volume, could prevent, or at least decrease the diffusion of small molecules.

\section{Permeability}

Non-metallized coatings: Water is a strongly polar molecule, whereas oxygen has no polarity at all, which means that their permeation through a substrate will be governed by different parameters. The diffusion of water molecules takes place by disrupting the hydrogen bonds existing in the structure, which implies the existence of hydrophilic groups. The water flow through a PET reference and the same reference coated with the cross-linked latexes (shell and core-shell) are shown in Figure 2.

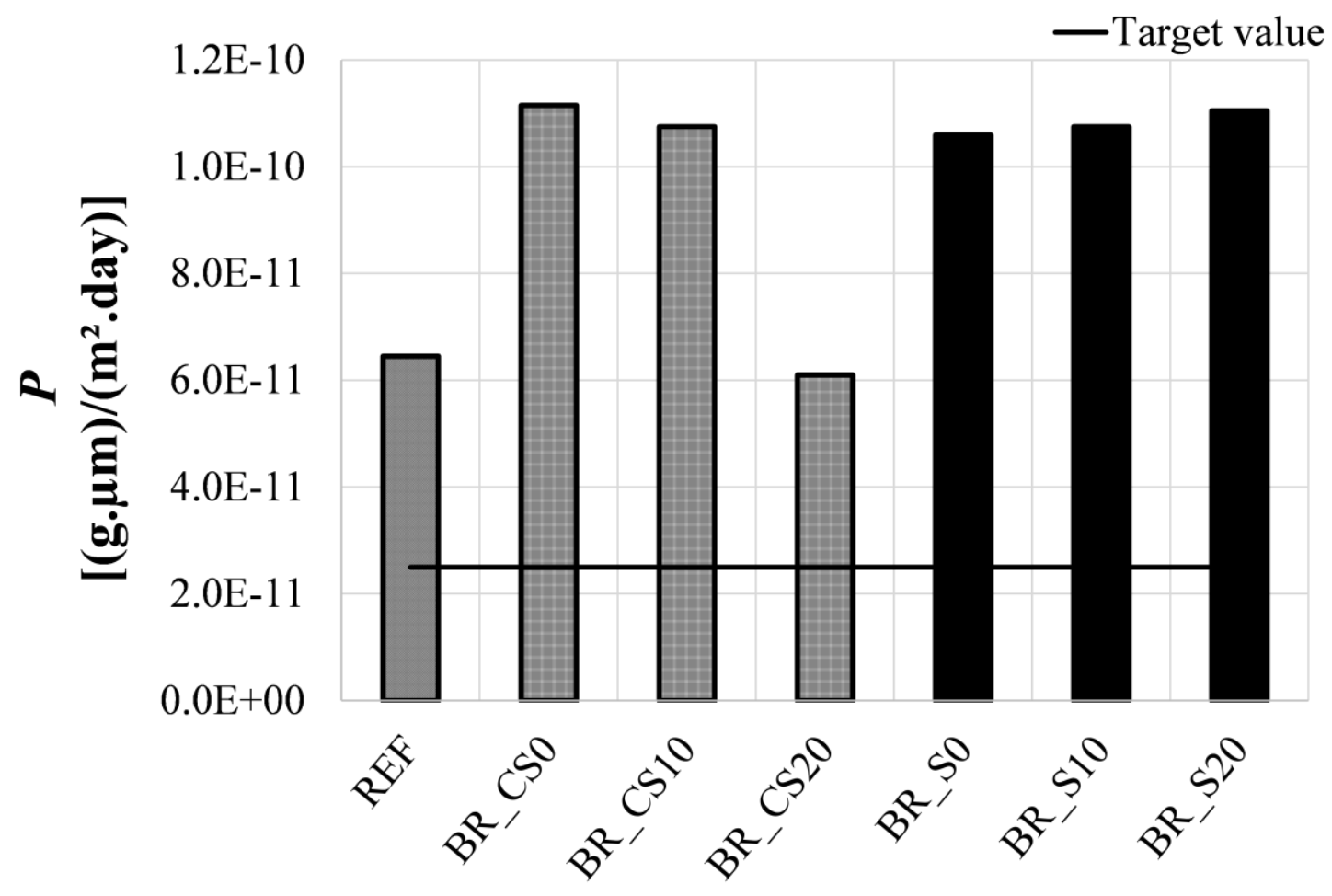

Figure 2. Water permeability for coatings formed by latexes with different amounts of crosslinker. REF bar represents the reference (uncoated PET), crosshatched bars represent the permeability of PET coated with core-shell particles, solid black bars represent the PET coated with non core-shell particles and the white bars represent the target values. Tests performed at $90 \% \mathrm{H} . \mathrm{R}$. at $38^{\circ} \mathrm{C}$, approximate dry film thickness $50 \mu \mathrm{m}$. 
One can observe that there is an increase in the water transmission rate (WTR) through the coated samples. We can offer different possible explanations for this result: (1) the existence of defects, which will create preferential pathways; (2) and/or the presence of carboxyl groups in the coating, which will be responsible for the plasticization of the structure; or (3) given that the flux of water across the medium is driven by chemical potentials, it is possible that the difference of chemical potential of water in the film on the coated PET is higher than that in the uncoated PET, thereby increasing the driving force for mass transfer.

Figure 3 shows the oxygen permeability for the coatings produced from the latexes synthesized with different amounts of crosslinking. By comparing it with the PET reference, a significant increase on oxygen permeation is observed. Unlike water, oxygen permeation is much more dependent on structural organization, which means that crystalline occlusions in the polymer matrix, or the presence of clays disposed perpendicular to the flow, could play important role in preventing gas passage (this is obviously not the case here). 


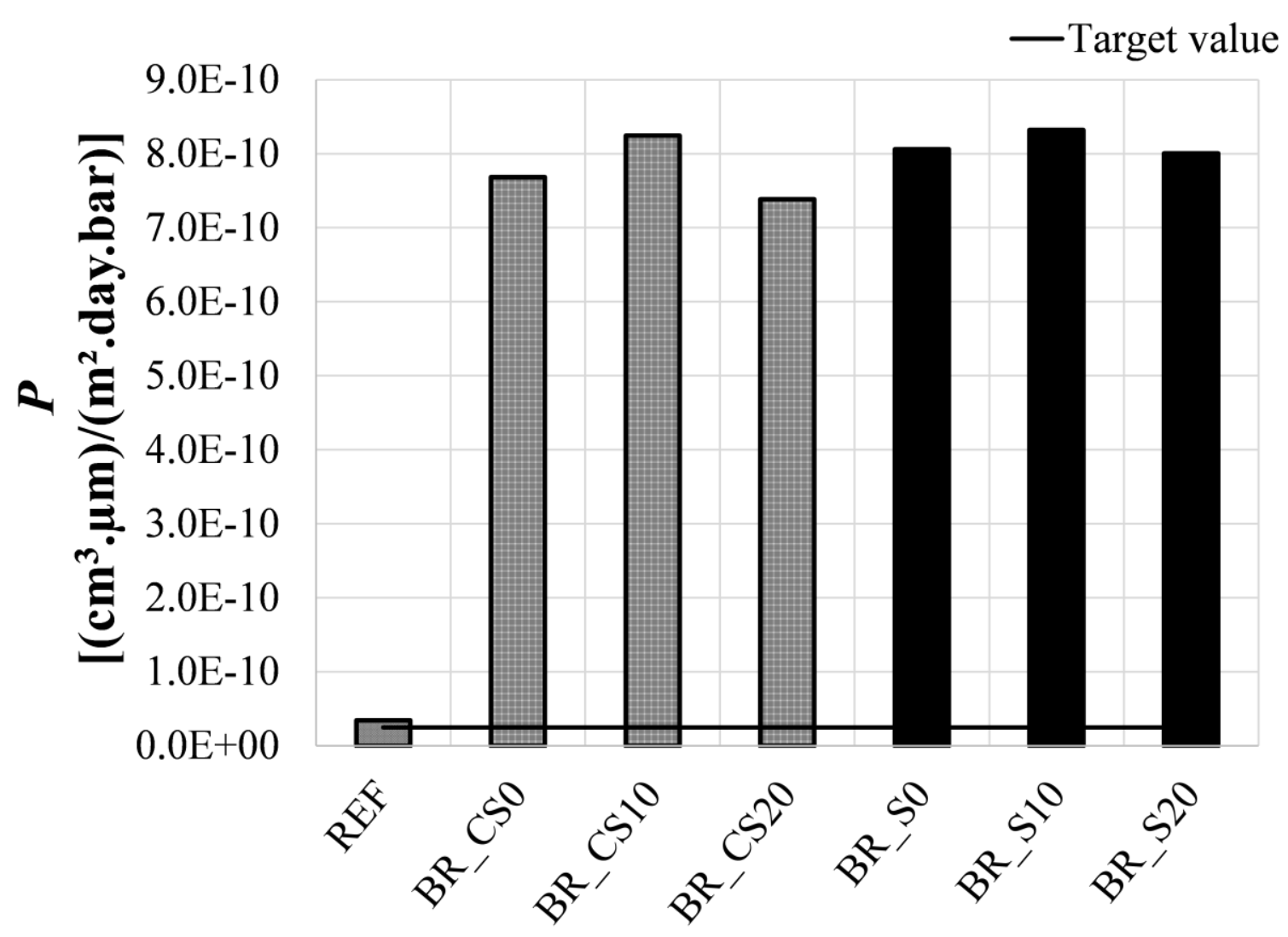

Figure 3. Oxygen permeability of coated PET. REF bar represents the reference (uncoated PET), crosshatched bars represent the permeability of PET coated with core-shell particles, solid black bars represent the PET coated with non core-shell particles and the white bars represent the target values. Tests performed at $0 \%$ of $\mathrm{HR}$, at $23^{\circ} \mathrm{C}$, approximate dry film thickness $50 \mu \mathrm{m}$.

These results show that our latexes alone are not useful barriers to moisture and/or oxygen. While the latex with the formulation presented here does not contribute positively to the barrier properties of the final material, its presence is necessary to promote the adhesion to aluminium using this type of product. We will therefore continue with the metallized coatings to see if the addition of an aluminium layer can circumvent this problem.

Metallized coatings: The coated films were metallized with aluminium, which was deposed onto the material under vacuum. A defect-free deposition of the metallic layer is imperative to its contribution to the barrier of the laminate. Adhesion tests were performed 
both at ambient conditions and after the sample was conditioned at $90 \%$ relative humidity for 24 hours. Results of the adhesion tests performed under dry and humid conditions are presented in Figure 4.

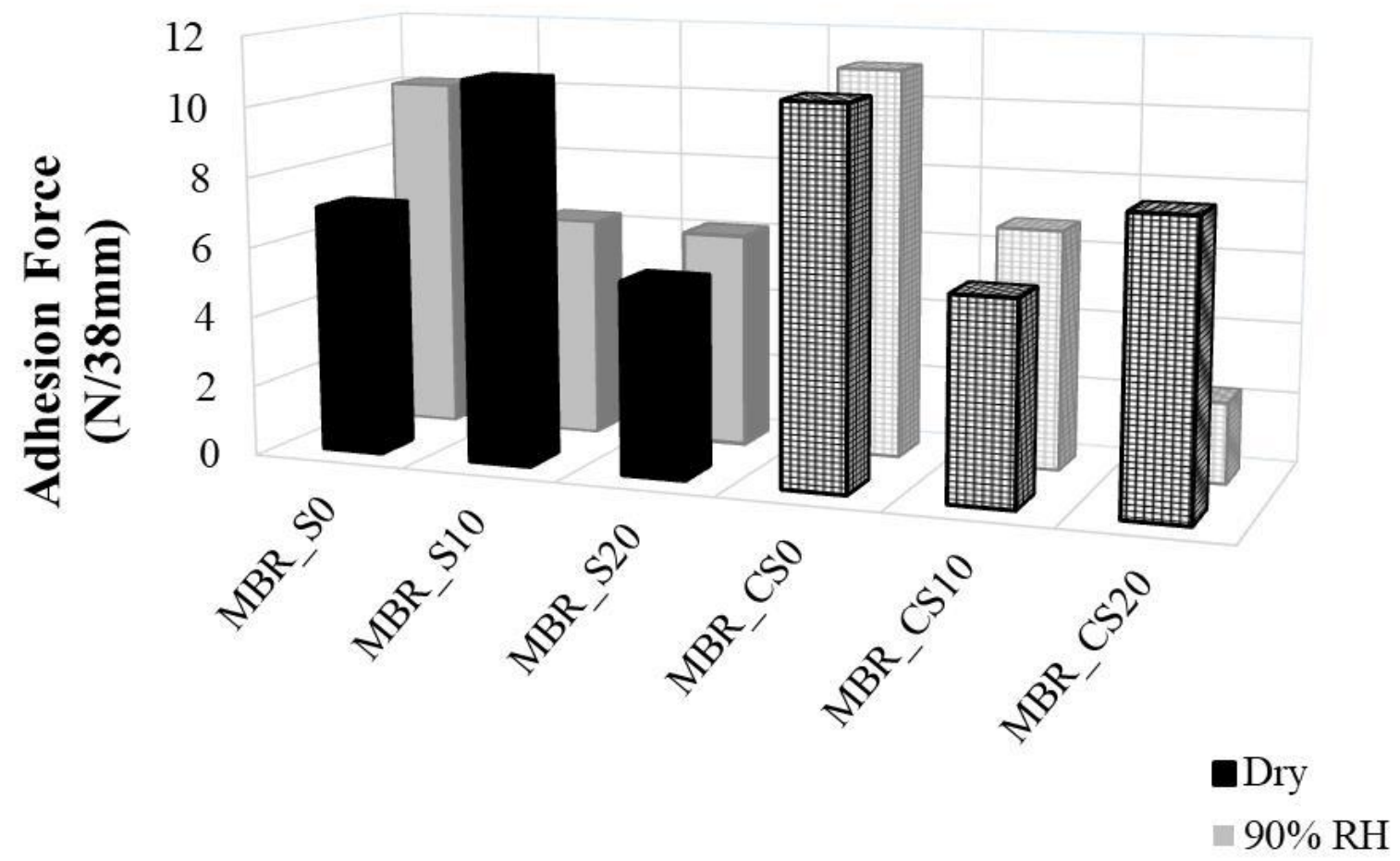

Figure 4. Adhesion force measured in dry films (black) and in films kept $24 \mathrm{~h}$ under $90 \%$ of relative humidity (grey). Crosshatched bars represent the adhesion of PET coated with coreshell particles, solid bars represent the PET coated with non core-shell particles.

The results presented on Figure 4 are quite promising in terms of promoting metal adhesion, even if the barrier properties of the adhesive layer are not outstanding. Jesdinszki et $a l^{52}$ evaluated the adhesion force between non-treated PET and metallic aluminium under dry conditions and they have found an average value of $1,5 \mathrm{~N} / 4 \mathrm{~cm}$. The values obtained in this work for the adhesion onto the functional latex ranged from 2 to $10 \mathrm{~N} / 4 \mathrm{~cm}$. This increase is expected to be related to the presence of carboxylic groups (from MAA) at the surface of the particles, as they are much more polar than the ester groups from PET. On the other hand, the effects of the presence of the core and the amount of cross-linker are not clear 
in terms of adhesion force. The films were able to maintain good adhesion in conditions of high humidity. This is a big challenge when working with materials that interact with hydrophilic groups like those from carboxylic acids. In the presence of humidity, such groups are expected to interact strongly with water molecules, which would lead to the delamination of the structure. This may be related to the fact that as MAA is the most hydrophilic monomer in the system it will be placed in the outer shell independently of the crosslinking degree and/or presence of a particle core, therefore the adhesion force would not be altered by those factors. As the adhesion force was not lost in conditions of high humidity, permeability tests were also performed in the laminated structure.

Figures 5 and 6 show the results for water and oxygen permeability tests respectively. They demonstrate that the permeability of the non-metalized films coated with latex formed by core shell and that offered by the non core-shell particles are similar. In the case of metallized films, it appears that the core-shell nanoparticles offer lower permeability to water than the non core-shell particles. This result is probably related to the fact that during film formation, given the hydrophilic character of the acidic functional groups (from methacrylic acid), they would preferentially be located at the surface of the particle. During the application of the metallic layer, these acidic groups would be available for direct interaction with the metal. On the other hand, non-polar $\mathrm{p}(\mathrm{S}-\mathrm{co}-\mathrm{BA})$ should form another layer able to bind 


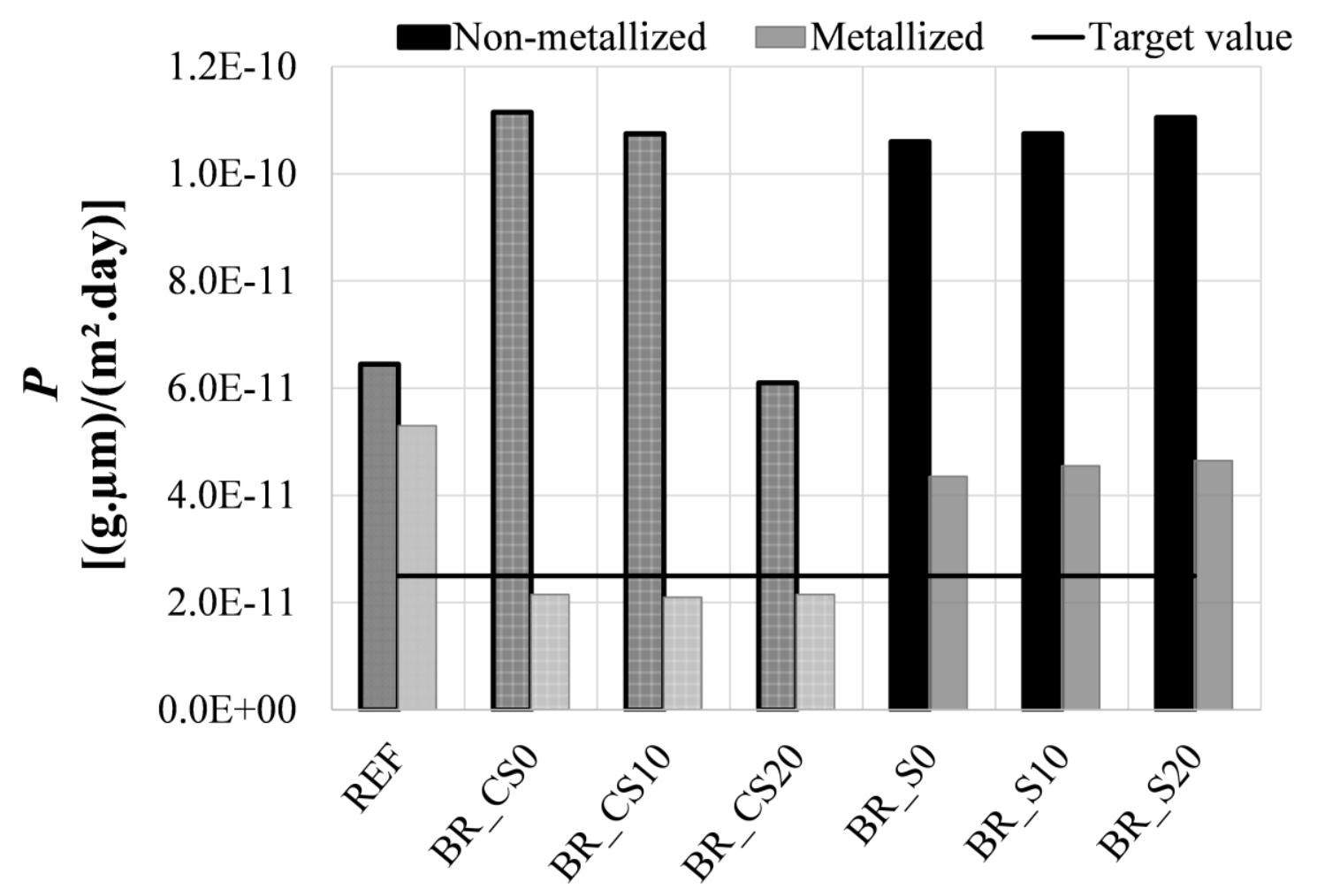

Figure 5. Water permeability for non-metallized (black bars) and metallized (grey bars) coatings formed by latexes with different amounts of crosslinker. REF dotted black bar represents the reference (uncoated and non-metallized PET), REF dotted grey bar represents uncoated metallized PET. Crosshatched bars represent the PET coated with core-shell particles, regular bars represent the PET coated with non core-shell particles and white bars represent the target value. Tests performed at $90 \%$ H.R. at $38^{\circ} \mathrm{C}$, approximate dry film thickness $50 \mu \mathrm{m}$. 


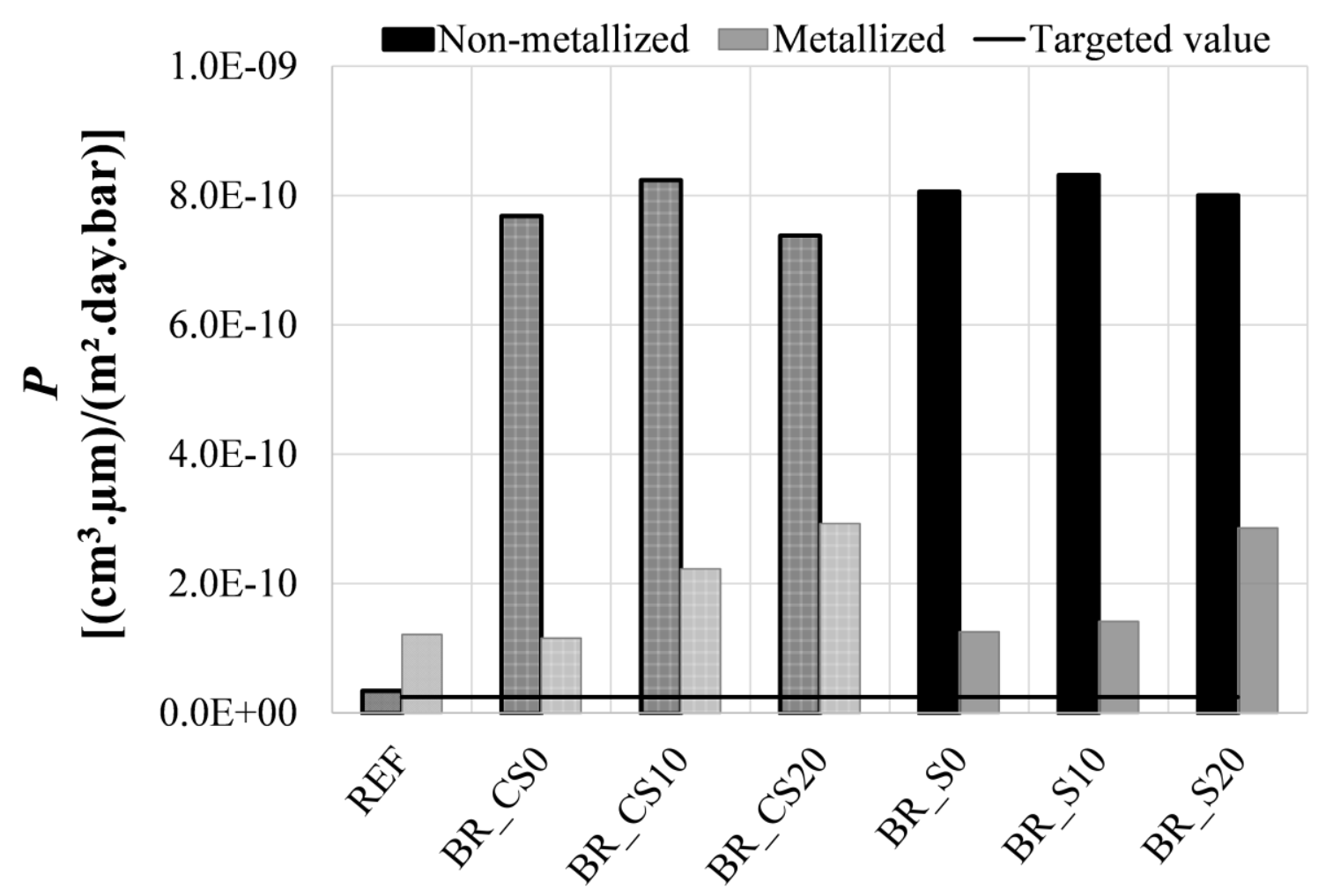

Figure 6. Oxygen permeability of non-metallized (black bars) and metallized (grey bars) coatings formed by latexes with different amounts of crosslinker. REF dotted black bar represents the reference (uncoated and non-metallized PET), and REF dotted grey bar represents uncoated metallized PET. Crosshatched bars represent the PET coated with coreshell particles, regular bars represent the PET coated with non core-shell particles and white bars represent the target value. Tests performed at $0 \%$ of $\mathrm{HR}$, at $23^{\circ} \mathrm{C}$, approximate dry film thickness $50 \mu \mathrm{m}$.

to the PET, which means that it is possible that the hydrophilic groups would be protected between the aluminium and the $\mathrm{p}(\mathrm{STY}-\mathrm{co}-\mathrm{BA})$. Nevertheless, it is clear that this result is not compatible with those obtained in the adhesion tests. The answer to this question may be the borders of the laminates. During the adhesion tests, the whole film is put inside a closed chamber at $90 \%$ relative humidity, which means that water molecules may penetrate inside the structure through the extremity of the film. This is not the case during the permeability tests, where infinite length may be considered for the film, since the borders are not in contact with water. On the other hand, when oxygen permeability is evaluated it seems that the amount of cross-linker in the system is more relevant than the morphology of the particles. According to Free Volume theory, the restriction of chain mobility would be 
mainly responsible for decreasing the diffusion through a given barrier, nevertheless the contrary is observed in Figure 6 where it can be seen that the higher the amount of EGDMA there is in the polymer, the more the oxygen seems to be able to diffuse through. It might be possible that increasing the amount of cross-linker means that it is harder for the chains to organise themselves in the matrix, thereby leading to an increase in the free volume and mobility of small molecules. It is also possible that the increased cross-linker causes the films to become brittle and thus to adhere less well to the PET surface. In both cases, metallization had a positive effect on the barrier property, as it was expected.

\section{Industrial Formulation and Barrier Property Evaluation}

Once we have demonstrated the interest in using core-shell particles as adhesives to enhance the barrier properties of a laminate, it is useful to take a look at the different steps required to formulate it for use in a commercial product. For instance, a wetting agent is required in order to ensure that the latex is correctly spread onto the PET surface when low levels of surfactant were employed. Such wetting agents are in fact polymeric emulsifiers that are known to enhance adhesive properties. They are generally added during the formulation step rather than during the polymerization in order to avoid nucleation of undesired particles. The second compound commonly used the formulation step is a curing agente to improve the characteristics of coatings during the step of film formation. ${ }^{2-6}$ The curing agent used in this work, HMMM promotes crosslinking between neighboring particles during the film formation. This helps to improve the mechanical resistance of the film, and the polar functional group in the HMMM aids in promoting a number of interactions with different substrates.

Two different processes were employed to deposit the coating onto the PET: (1) at laboratory scale by using a hand-coater and (2) at an industrial line for PET extrusion. The laboratory 
scale process was used as a preliminary screening tool, and the results are presented in the supplemental material; only the results of the industrial trials are presented here. The properties of the final laminates will depend on the process. During the coating step at the industrial extrusion line, the laminate is submitted to the biaxial stretching, which organizes the PET chains, and consequently increases its crystallinity to approximately $56 \%$ after stretching. The increased crystallinity can improve the barrier properties, however since the adhesive coating is deposited before the film is stretched, this stretching step might have some effect on the distribution of the film onto the polymeric substrate. The stretching is carried out in an oven at a temperature of $180^{\circ} \mathrm{C}$ and the process takes approximately 3 minutes. This means that water will evaporate from the film at a significant rate, which might induce the formation of defects in the coating. In addition, the stretching may lead to the generation of holes in the structure. Since the film is not stretched in the lab scale process, the crystallinity is low and the film thicker, making it difficult to optimize the industrial process based on the lab scale one. Furthermore, the deposition of the coating in the industrial line is much more uniform than the deposition performed at laboratory scale with the hand coater.

The MAEEU contains a methacrylamide group, so when added to the latex it promotes adhesion to metallic substrates even under conditions of high humidity and should enhance the adhesive characteristics of the latex. The amount of MAEEU was varied from 1 to $5 \% \mathrm{wt}$ with respect to the total amount of monomer used in the polymerization. The latexes were also formulated with the wetting agent Wisester N530 and the curing agent HMMM. Note that in order to evaluate only the influence of the functional monomer, the non-formulated latexes were also evaluated on the pilot trials. A summary of the characteristics of the latexes selected for pilot trial is presented in Table 3, and the different formulations are given in * with respect to the total amount of polymer present in the latex. 
Table 4.

Table 3. Summary of the latexes used in the pilot trial.

\begin{tabular}{|c|c|c|c|c|c|}
\hline & \multicolumn{3}{|c|}{ Shell } & \multicolumn{2}{|c|}{ Core } \\
\hline Latex & $\begin{array}{l}\text { MAEEU } \\
(\% w t)^{*}\end{array}$ & $\begin{array}{c}\text { EGDMA } \\
(\% w t)^{*}\end{array}$ & $\begin{array}{c}T_{g} \\
\text { experimental } \\
\left({ }^{\circ} \mathrm{C}\right)\end{array}$ & $\begin{array}{c}\text { Core } \\
\text { composition }\end{array}$ & $\begin{array}{c}\text { Core } \\
T_{g(\text { experimental })} \\
\left({ }^{\circ} \mathrm{C}\right)\end{array}$ \\
\hline$B R \_S P I$ & 1 & - & 33 & $\mathrm{P}(\mathrm{STY}-c o-\mathrm{BA})$ & 83 \\
\hline$B R \_S P 2$ & 5 & - & 35 & $\mathrm{P}(\mathrm{STY}-c o-\mathrm{BA})$ & 85 \\
\hline$B R \_S P 3$ & 3 & - & 35 & $\mathrm{P}(\mathrm{STY}-c o-\mathrm{BA})$ & 82 \\
\hline$B R \_S P 4$ & 2 & 2 & 35 & $\mathrm{P}(\mathrm{STY}-c o-\mathrm{BA})$ & 82 \\
\hline
\end{tabular}

* with respect to the total amount of polymer present in the latex.

Table 4. Formulations used in the pilot trial.

\begin{tabular}{|c|c|c|c|c|c|}
\hline Latex & Caption & $\begin{array}{c}\text { Wetting agent } \\
\text { Wisester N530 } \\
(\% w t)^{*}\end{array}$ & $\begin{array}{c}\text { HMMM } \\
\text { Curing agent } \\
(\% w t)^{*}\end{array}$ & S.C. $(\%)$ & $\begin{array}{c}\text { PET } \\
\text { thickness } \\
(\mu m)\end{array}$ \\
\hline \multirow{3}{*}{$B R \_S P 1$} & PT-R1 & - & - & 15.0 & 8 \\
\hline & PT-F117 & 4 & 2 & 15.0 & 8 \\
\hline & PT-F121 & 4 & 10 & 15.0 & 8 \\
\hline \multirow{3}{*}{$B R \_S P 2$} & PT-R2 & - & - & 15.0 & 8 \\
\hline & PT-F122 & 4 & 2 & 15.0 & 8 \\
\hline & PT-F126 & 4 & 10 & 15.0 & 8 \\
\hline \multirow{3}{*}{$B R \_S P 3$} & PT-R3 & - & - & 15.0 & 8 \\
\hline & PT-F127 & 4 & 2 & 15.0 & 8 \\
\hline & PT-F131 & 4 & 10 & 14.9 & 8 \\
\hline \multirow{3}{*}{$B R \_S P 4$} & PT-R4 & - & - & 15.0 & 8 \\
\hline & PT-F132 & 4 & 2 & 15.0 & 8 \\
\hline & PT-F135 & 4 & 10 & 15.0 & 8 \\
\hline
\end{tabular}

* with respect to the total amount of polymer present in the latex

Figure 7 shows the adhesive force for the samples conditioned at $0 \%$ of relative humidity, where it can be seen that, at low concentrations ( 1 and $2 \%$ wt with respect to the total monomer present in the system), the MAEEU seems to contribute mainly to the adhesive force. The presence of the methacrylamide group is likely to be responsible for the increase on the adhesion force with respect to the unformulated latex. On the other hand, at high concentrations of this monomer (above $3 \%$ wt with respect to the total monomer) a significant amount of coagulum was observed in the latexes. The reason for this is that the MAEEU is positively charged so it tends to neutralize the negative charges of the surfactant, thereby destabilizing the latex. In such case, the functional monomer does not polymerize 
with the other monomers sued for the latex, but rather is drawn to the particle surface and neutralizes the surfactant. When this happens, the number of methacrylamide groups on the surface of the remaining particles (if any) is not enough to promote the adhesion. As a result, at higher levels of MAEEU, we observe that the adhesive force increases with the curing agent content, which alone will be the responsible for promoting the adhesion

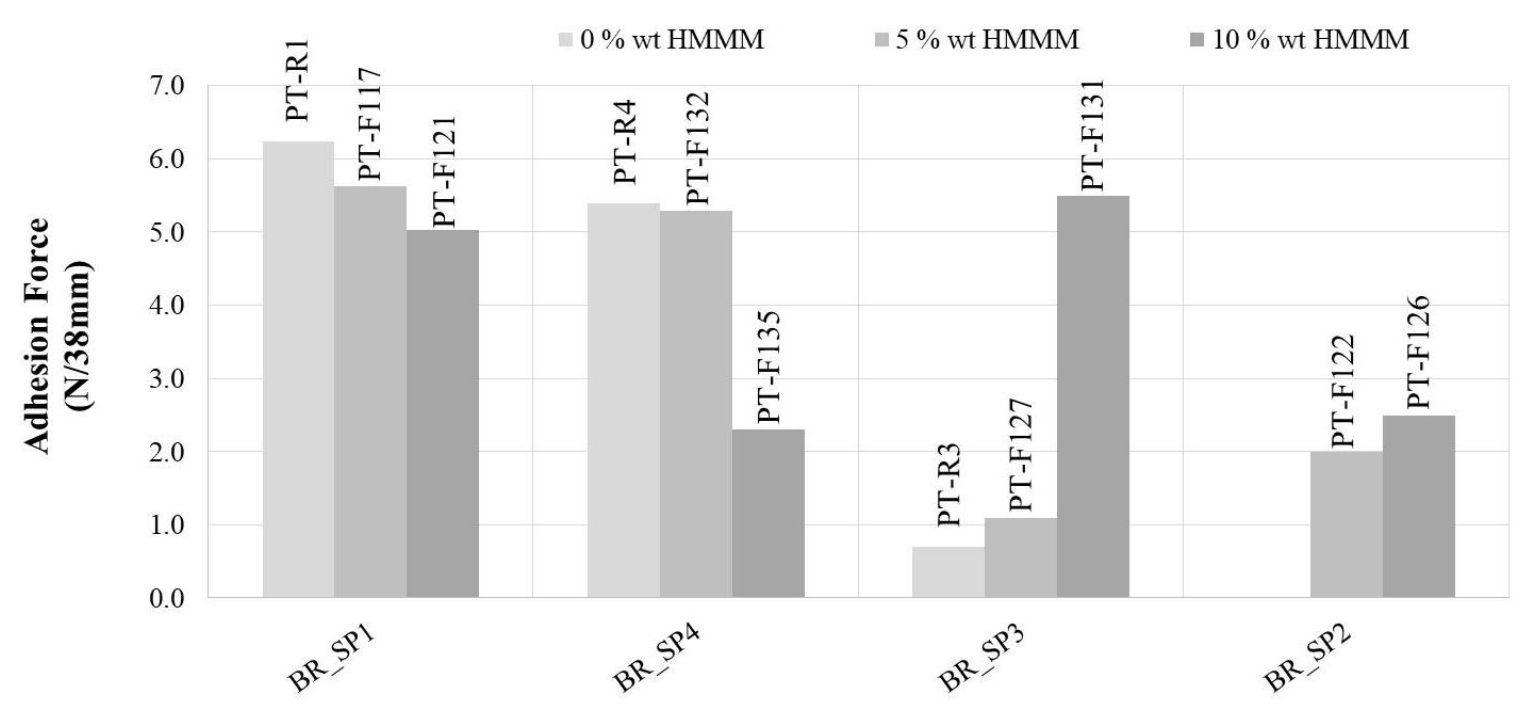

Figure 7. Adhesion force measured on the dried films containing different amounts of curing agent. The base latexes used in the presented formulations were synthesized with different amounts of MAEEU. 


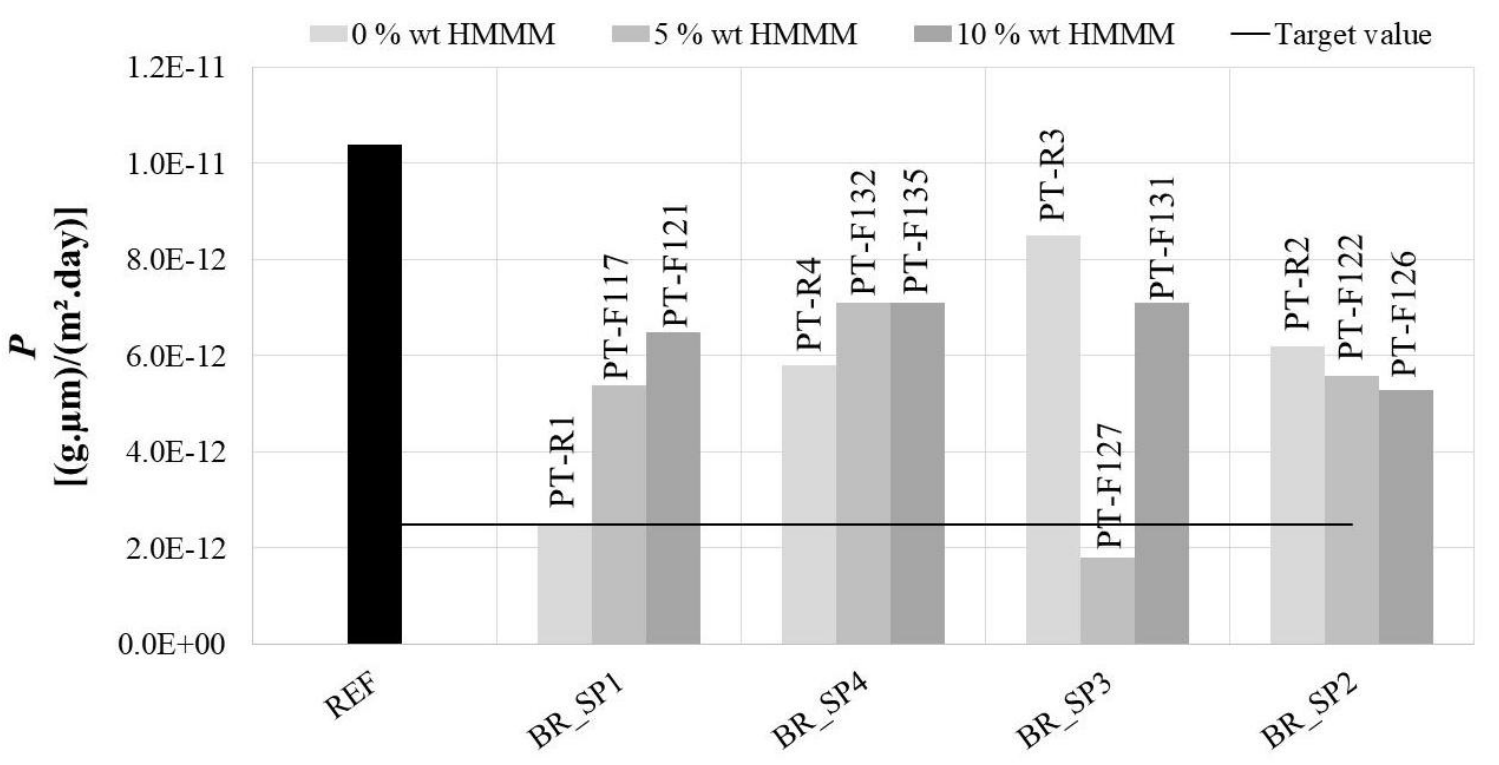

Figure 8. Water permeability of metallized films coated with latexes with different amounts of MAEEU. Tests performed at $90 \%$ H.R. at $38^{\circ} \mathrm{C}$, approximate dry film thickness $50 \mu \mathrm{m}$.

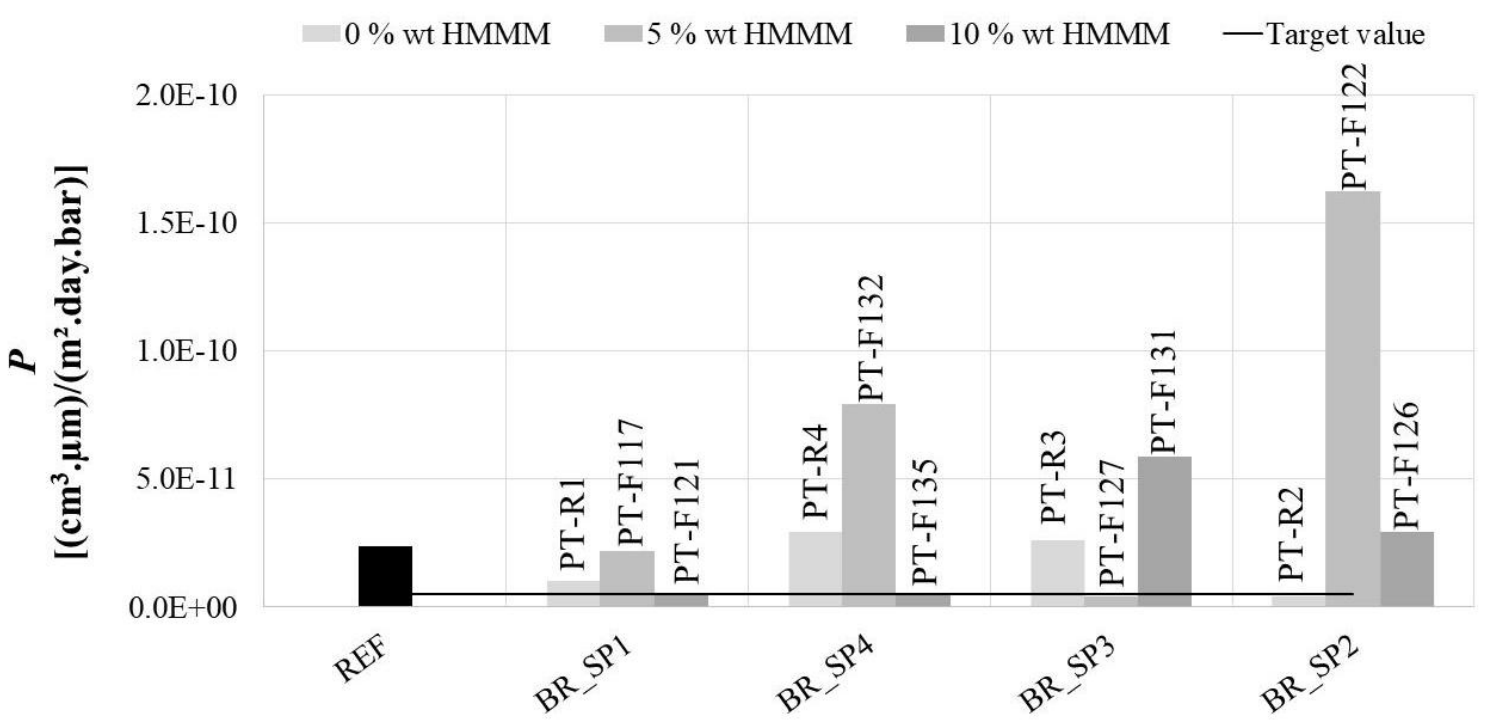

Figure 9. Oxygen permeability of metallized films coated with latexes with different amounts of MAEEU. Tests performed at $0 \%$ of $\mathrm{HR}$, at $23^{\circ} \mathrm{C}$, approximate dry film thickness $10 \mu \mathrm{m}$.

Figures 8 and 9 show water and oxygen permeability for the systems synthesized with different concentrations of MAEEU, respectively. The water permeability follows a trend similar to that of the the adhesion measured at $0 \%$ of relative humidity. Figure 8 shows that for the coatings without external crosslinker, the lower the amount of MAEEU is, the lower the permeability. The curing agent effect on water permeability is positive only at higher 
concentrations of functional monomers. The permeability to oxygen is significantly lower for the systems containing low concentrations of MAEEU. This is a result of the efficiency of the metallic layer due to the high adhesive force of the systems containing MAEEU. The coatings formed from latexes containing higher amounts of MAEEU show no changes with respect to further increases in MAEEU or curing agent. It is possible to attribute this to the destabilization of the system; a result of the coagulation that took place when inserting the positively charged monomer into the system. Nevertheless, the results obtained for coatings synthesized with latexes BR_SP1 and BR_SP4 are very promising. The main interest in employing MAEEU is its ability to maintain adhesion under severe conditions, including conditions of high humidity. As was discussed more than once in the scope of this work, hydrophilic groups are capable of promoting the adhesion between polymers and metals. Nevertheless, these same groups are very likely to be disturbed by moisture, mainly water molecules. The presence of the hydrophobic methacrylamide group on MAEEU, decreases the water sensitivity, with no or little compromise of polar groups. This is the reason why this compound is widely used as an adhesion promoter in conditions of high humidity. Figure 10 shows the adhesion force measured in samples that were conditioned at $90 \%$ relative humidity during $24 \mathrm{~h}$.

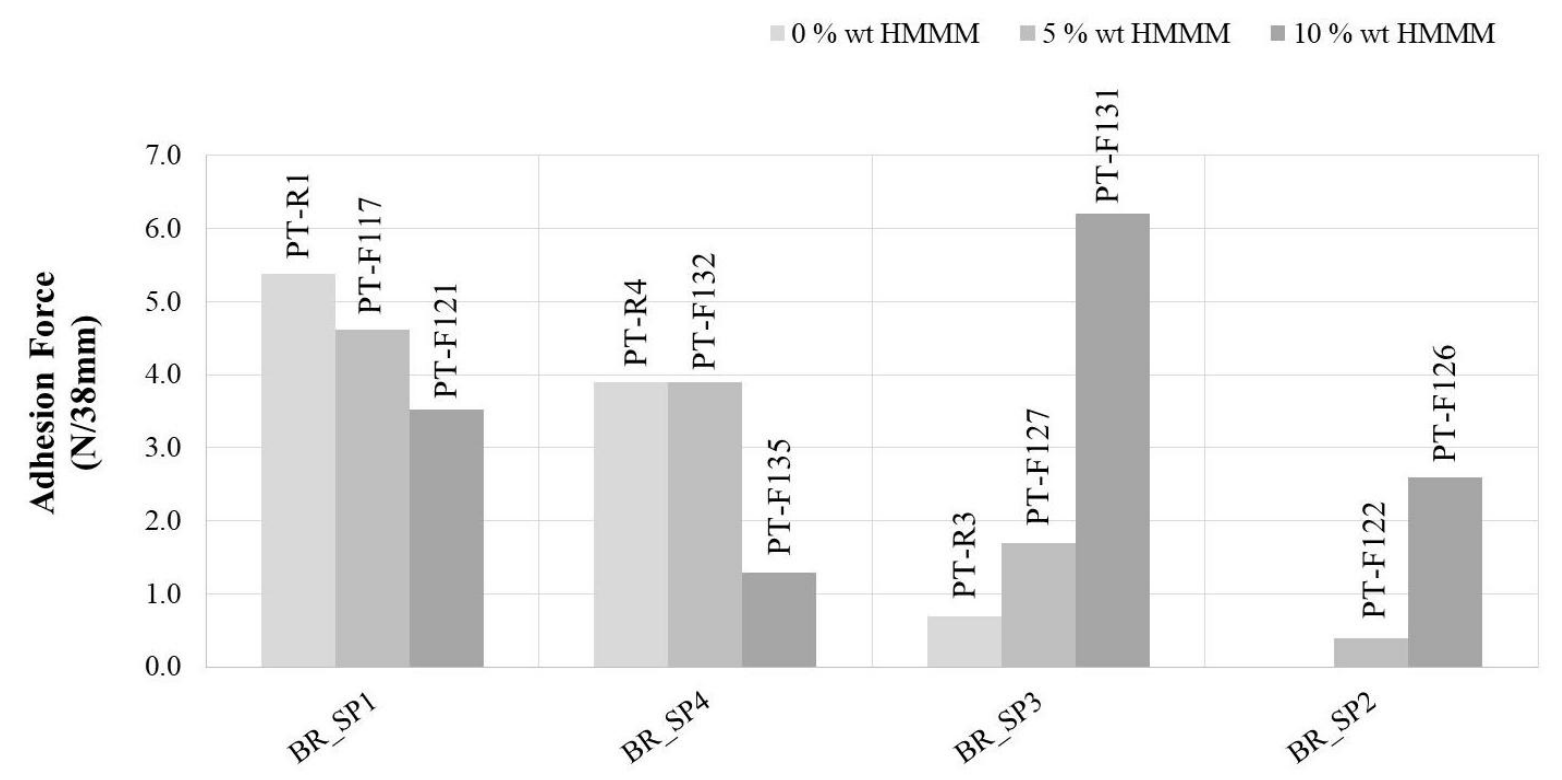


Figure 10 Adhesion force measured on samples conditioned at $90 \%$ R.H. with different amounts of curing agent. The base latexes used in the presented formulations were synthesized with different amounts of MAEEU.

Comparing Figures 7 and 10, one may note that the adhesion force remained nearly constant when measured at 0 and $90 \%$ of relative humidity for the two first series of coatings. This is evidence that the MAEEU is somehow contributing actively to the adhesion to the aluminium. The coatings formulated by using latexes containing more than $3 \% \mathrm{wt}$ of MAEEU, were found to be under the influence of the curing agent. The adhesion force increased slightly when increasing the amount of this compound.

\section{Conclusions}

A study of the influence of the presence or absence of an hydrophobic seed in an acrylic latex was studied in terms of the adhesive strength, and permeability to oxygen and water when used to promote the adhesion of an aluminium layer on a PET substrate. In the case of the core-shell particles (i.e. with an hydrophobic seed), the impact of crosslinking the shell was also examined. The coated PET substrates prepared from these latexes were analysed before and after metallization. The non-metallized coatings were found to have a permeability higher than the reference itself, which is due to the fact that the polymers formed have no main features aimed to prevent the existence of free volume that would facilitate the permeation of small molecules. Crosslinking and the presence/absence of a core had no significant effect on this outcome. Metallic adhesion was evaluated at ambient conditions and at $90 \%$ of relative humidity was measured. The adhesive force was found to be similar for all of the latexes (with and without a seed), most likely because they all have 
the same amount of methacrylic acid in their composition, and this would be the compound principally responsible for promoting the adhesion between the PET substrate and the metal. Furthermore, the permeability drops by half in when the latex particles contain a hydrophobic core with respect to that of particles made only of the shell (adhesive) material. On the other hand, the crosslinker had no major influence on the water permeability. The oxygen permeability increased when the quantity of EGDMA was increased. This was attributed to the crosslinking density, which would be responsible for the formation of longer bonds, and in that case mobility would not be prevented, facilitating the diffusion of this gas. While the presence of the hydrophobic core decreased water permeability, it appeared to have no measurable effect on oxygen permeability.

In terms of evaluating the performance of industrial formulations using the core-shell particles, it was found that wetting agent is necessary to ensure the good spreading of the coating. Furthermore, the Wisester N530 presents sulphate functional groups which were found to contribute to the metallic adhesion in the absence of humidity, but under conditions of severe humidity, this compound suffers plasticization causing the complete delamination of the structure. It is therefore important to use the minimum necessary amount of this particular wetting agent. Furthermore, increasing the content of the curing agent HMMM with respect to the total polymer present in the latex, had a positive effect on water permeability until a certain value. This value was dependent mainly on the latex being used on the base formulation; the higher the concentration of crosslinker in the base latex, the less curing agent should be used in the formulation to avoid producing a brittle film. We have attributed this result to the condensation of this compound, which could form a layer of a glassy HMMM that would impede the interaction between the metallic aluminium and the coating. No trend was observed relating the amount of this compound used in the formulation and the oxygen permeability. Furthermore, for the adhesion tests performed at 
$90 \%$ of relative humidity, the increase of HMMM content had a positive effect on the adhesion.

In conclusion, the best way to improve the barrier property of an acrylic coating is by using a functional monomer in the base latex in order to improve the adhesion to metals. It was proven that even in very low concentrations, such monomers are able to ensure that the structure will not delaminate even in severe conditions, such as high temperature and humidity. As a result, the metal layer will be fully responsible for preventing the passage of small molecules, ensuring that the structure works properly as a barrier.

\section{Acknowledgments}

Authors BRL and TFLM are grateful to Toray Films Europe for the financial support and permeability analyses, and M. Pierre-Yves Dugas for cryo-TEM analysis.

\section{References}

1. R.A. Wessling, Polyvinylidene chloride. Gordon and Breach Science Publishers New York: 1977.

2. D. Ballard, A. Burgess, J. Dekoninck, E. Roberts, Polymer 1987, $28,3$.

3. M. Gilbert, J. Macromol Sci., Part C: Polymer Reviews 1994, 34, 77.

4. B. Howell, D. Beyer, Vinylidene Chloride Polymers, 2011, Vinylidene chloride polymers. In Encyclopedia of Polymer Science and Technology $4^{\text {th }}$ Edition Mark, H.F. (Ed.), pp. 35-43. Hoboken, NJ, USA: Wiley

5. K.K. Mokwena, J. Tang, Crit. Rev. Food Sci. Nutr. 2012, 52, 640

6. W. Schrenk, T.S. Alfrey, Polym. Eng. Sci., 1969, 9, 393.

7. M. Lim, D. Kim, J. Seo, Polym. Int., 2016, 65, 400.

8. P. Kofinas, R.E. Cohen, A.F. Halasa, Polymer 1994, 35, 1229. 
9. A.W. Thornton, K.M. Nairn, A.J. Hill, J.M. Hill, J. Membrane Sci., 2009, 338, 29.

10. M.J. Devon, J.L. Gardon, G. Roberts, A. Rudin, J. Appl. Polym. Sci., 1990, 39, 2119.

11. H.B. Kim, Y. Wang, M.A. Winnick, Polymer, 1994, 35, 1779

12. F. Huijs, J. Lang, Coll. Polym. Sci., 2000, 278, 746

13. J.A. Gonzalez-Leon, S.W. Ryu, S.A. Hewlett, S.H. Ibrahim, A.M. Mayes, Macromol., $\mathbf{2 0 0 5}, 38,8036$

14. E. Limousin, N. Ballard, J.M. Asua, J. Appl. Polym. Sci., 2019, 136, doi: https://doi.org/10.1002/app.47608

15. E. Limousin, N. Ballard, J.M. Asua, Progress in Organic Coatings, 2019,129, 69

16. A.W. Thornton, K.M. Nairn, A.J. Hill, J.M. Hill, Y. Huang, J. Membrane Sci., 2009, 338,38 .

17. J.E. Jönsson, O.J. Karlsson,H. Hassander, B.Törnell, Eur. Polym. J., 2007, 43, 1322

18. Z.G. Liu, Y. Han, C. Zhou, M.Y. Zhang, W.M. Li, H.X. Zhang, F.Q. Liu, W.J. Liu, Ind. Eng. Chem. Res. 2010, 49, 7152

19. I. Hasanzadeh, A.R. Mahdavian, H. Salehi-Mobarakeh, Prog. Org. Coat. 2014, 77, 1874

20. Z. Song, E.S. Daniels, E.D. Sudol, A. Klein, M.S. El-Aasser, Colloid Polym. Sci. 2014, 292,645 .

21. I.W. Cheong, J.H. Kim, Macromol. Theory Simul. 1998, 7, 49

22. O.J. Karlsson,H. Hassander, D. Colombini, Comptes Rendus Chimie 2003, 6, 1233.

23. L.W. Morgan, J. Appl. Polym. Sci. 1982, 27 (6), 2033-42.

24. E. Unzueta, J. Forcada, Polymer 1995, 36, 1045.

25. R. Ghosh Chaudhuri, S. Paria, Chem. Rev. (Washington, DC, U. S.) 2012, 112, 2373.

26. X. Du, X. Liu, H. Chen, J. He, J., J. Phys. Chem. C 2009, 113, 9063.

27. D. Lee, T. Ishikawa, J. Polym. Sci.: Polym. Chem., 1983, 21, 147.

28. Z. Nie, S. Xu, M. Seo, P.C. Lewis, E. Kumacheva, JACS, 2005, 127, 8058.

29. M. Okubo, A. Yamada, T. Matsumoto, J. Polym. Sci.: Polym. Chem 1980, 18, 3219.

30. L.J. Gonzalez-Ortiz, J.M. Asua, Macromolecules 1995, 28, 3135.

31. V. Herrera, R. Pirri, J.M. Asua, J.R. Leiza, J. Polym. Sci. Part A: Polym. Chem. 2007, 45, 2484. 
32. V.M. Carranza Oropeza, Síntese e caracterização de nanopartículas núcleo-casca de poliestireno e polimetacrilato de metila obtidas por polimerização em emulsão sem emulsificante e fotoiniciada, 2012, Universidade de São Paulo.

33. Y.C. Chen, V. Dimonie, M. El-Aasser, M., Pure Appl. Chem. 1992, 64, 1691.

34. V. Mittal, Advanced polymer nanoparticles: synthesis and surface modifications. 2010, CRC Press, Colchester (UK)

35. D.C. Sundberg, A.P. Casassa, J. Pantazopoulos, M.R. Muscato, B. Kronberg, J. Berg, J. Appl. Polym. Sci., 1990, 41, 1425.

36. D.C. Sundberg, Y.G. Durant, Polym. React. Eng. 2003, 11, 379.

37. C.F. Lee, J. Polym. Sci., Part A: Polym. Chem. 2005, 43, 2224.

38. J. Berg, D. Sundberg, B. Kronberg, J. Microencaps., 1989, 6, 327.

39. C. Schellenberg, S. Akari, M. Regenbrecht, K. Tauer, F. Petrat, M. Antonietti, Langmuir, 1999, 15, 1283.

40. C. Schellenberg, K. Tauer, M. Antonietti, Macromol. Symp., 2000, 151, 465

41. O. Kalinina, E. Kumacheva, Macromolecules 2001, 34, 6380.

42. J.M. Stubbs, D.C. Sundberg, J. Appl. Polym. Sci., 2006, 102, 2043.

43. L.E. Karlsson, O.J. Karlsson, D.C. Sundberg, D. C., N J. Appl. Polym. Sci., 2003, 90 (4), 905-915.

44. J.M. Stubbs, O.J. Karlsson, J.E. Jönsson, E. Sundberg, Y.G. Durant, D.C. Sundberg, Colloids and Surfaces A: Physicochemical and Engineering Aspects 1999, 153, 255.

45. S.C. George, S. Thomas, Prog. Polym. Sci. 2001, 26, 985.

46. V. Siracusa, V., Int. J. Polym. Sci. 2012, 302029, 11.

47. N. Yi-Yan, R.M. Felder, W.J. Koros, J. Appl. Polym. Sci. 1980, 25, 1755.

48. J. Gajdoš, K. Galić, Z. Kurtanjek, N. Ciković, Polym. Test. 2000, 20, 49.

49. P. Neogi, P., Diffusion in polymers. 1996; Marcel Deker (New York, USA)

50. H.D. Kamaruddin, W.J. Koros, W. J., J. Memb. Sci., 1997, 135, 147.

51. A.Y. Alentiev, Y.P.Yampolskii, J. Memb. Sci. 2000, 165, 201.

52. J.M. Zielinski, J. Duda, AIChE Journal 1992, 38, 405.

53. N.S. Sangaj, V.C. Malshe, Prog. Org. Coat. 2004, 50, 28.

54. W.J. Muizebelt, W.J.M. Heuvelsland, Polym. Mater. Sci. Eng. 1985, 53, 454. 
55. G. Unnikrishnan, S. Thomas, S., Polymer 1994, 35, 5504.

56. B.M. Perfetti, Metal surface characteristics affecting organic coatings. 1994, Federation of Societies for Coatings Technology, Blue Bell, PA (USA)

57. M. Schneider, C. Graillat, S. Boutti, S.; T.F.L. McKenna, Polym. Bull. 2001, 47, 269.

58. M. Jesdinszki, C. Struller, N. Rodler, D. Blondin, V. Cassio, E. Kucukpinar, H.C. Langowski, J. Adhes. Sci. Technol. 2012, 26, 2357.

59. W. Brostow, R. Chiu, I.M. Kalogeras, A. Vassilikou-Dova, Mat. Lett. 2008, 62, 3152.

60. J.M. Stubbs, D.C. Sundberg, J. Appl. Polym. Sci., 2006, 102, 945.

61. J.M. Lagarón, Multifunctional and nanoreinforced polymers for food packaging. 2011, Woodhead Publishing, Cambridge (UK). 